\title{
Expression and Localization of an Hsp70 Protein in the Microsporidian Encephalitozoon cuniculi
}

\author{
Carrie E. Jolly, Cory A. Leonard, and J. Russell Hayman \\ Department of Microbiology, James H. Quillen College of Medicine, East Tennessee State University, Box 70579, Johnson City, \\ TN 37614, USA \\ Correspondence should be addressed to J. Russell Hayman, hayman@etsu.edu
}

Received 19 April 2010; Accepted 22 June 2010

Academic Editor: Robert P. Gunsalus

Copyright ( 2010 Carrie E. Jolly et al. This is an open access article distributed under the Creative Commons Attribution License, which permits unrestricted use, distribution, and reproduction in any medium, provided the original work is properly cited.

Microsporidia spore surface proteins are an important, under investigated aspect of spore/host cell attachment and infection. For comparison analysis of surface proteins, we required an antibody control specific for an intracellular protein. An endoplasmic reticulum-associated heat shock protein 70 family member (Hsp70; ECU02_0100; "C1") was chosen for further analysis. DNA encoding the $\mathrm{C} 1 \mathrm{hsp} 70$ was amplified, cloned and used to heterologously express the $\mathrm{C} 1 \mathrm{Hsp} 70$ protein, and specific antiserum was generated. Two-dimensional Western blotting analysis showed that the purified antibodies were monospecific. Immunoelectron microscopy of developing and mature E. cuniculi spores revealed that the protein localized to internal structures and not to the spore surface. In spore adherence inhibition assays, the anti-C1 antibodies did not inhibit spore adherence to host cell surfaces, whereas antibodies to a known surface adhesin (EnP1) did so. In future studies, the antibodies to the 'C1' Hsp70 will be used to delineate spore surface protein expression.

\section{Introduction}

Microsporidia are spore-forming, obligate intracellular divergent fungi with an extensive host range that includes most vertebrates and invertebrates. Although the first species of microsporidia was described over 150 years ago, microsporidiosis was rarely diagnosed in humans prior to the AIDS pandemic. Today, microsporidia are recognized as opportunistic pathogens of humans [1]. Most microsporidia infections in humans are thought to arise via the fecal-oral route. Ingestion of the environmentally stable spores leads to primary infection in the small intestine where replication of the organisms results in destruction of the epithelium. Therefore, the most common clinical manifestations of microsporidiosis are self-limiting diarrhea in immunocompetent individuals and persistent diarrhea perhaps leading to a wasting syndrome in the immunocompromised [2].

All microsporidia possess a unique invasion apparatus known as the polar tube or polar filament, which must be discharged in order to infect the host cell. Upon extrusion, the polar tube penetrates the host cell plasma membrane and allows the passage of infectious sporoplasm from the spore through the hollow polar tube into the host cell cytoplasm where replication occurs. We hypothesize that infection of the host cell is facilitated by adherence of the microsporidia spore to the host cell surface prior to or during the activation process. Our previous studies have demonstrated that microsporidia spores of the genus Encephalitozoon adhere to the host cell surface in vitro through at least one mechanism involving host cell glycosaminoglycans [3]. In vitro spore adherence and host cell infectivity assays demonstrate that addition of exogenous sulfated glycosaminoglycans to the culture medium results in decreased spore adherence and decreased number of infected host cells. Our studies indicate a direct association between microsporidia adherence to the host cell surface and infectivity.

To understand the mechanism of microsporidia adherence, we have turned our attention to identifying possible ligands on the spore surface. Putative proteins with recognizable adhesion domains are identified by searching the Encephalitozoon cuniculi genome database with adhesion/ attachment motifs. Identified proteins are heterologously expressed, purified, and used for antibody production. We are using previously developed assays to evaluate the 
recombinant proteins and their corresponding antibodies as potential inhibitors of spore adherence and/or host cell infectivity. For comparison purposes, we require a microsporidia protein that is not located on the spore surface and does not inhibit spore adherence or infectivity. Because heat shock proteins (Hsps) are typically found in the cytosol, ER, and mitochondria of a cell [4], we chose to examine the Hsp70related proteins from E. cuniculi as potential candidates. In this study, we demonstrate by transmission immunoelectron microscopy that the Hsp70-related protein (ECU02_0100) is located in internal structures of the spore. We also show that antibodies against the recombinant Hsp70-related protein C1 do not significantly inhibit spore adherence or host cell infection in vitro. Recombinant Hsp70 protein and the antibodies against this protein will be used for comparison purposes in our quest to identify possible microsporidia spore ligands that function during adherence.

\section{Materials and Methods}

2.1. Microsporidia and Host Cell Cultivation. African green monkey kidney cells (Vero; ATCC CCL-81) and rabbit kidney cells (RK-13; ATCC CCL-37) were used for the cultivation of microsporidia spores. Adherent cells were maintained in Dulbecco's modified Eagle's medium (BioWhittaker, Walkersville, MD) supplemented with L-glutamine $(2 \mathrm{mM})$, penicillin $(100 \mathrm{U} / \mathrm{mL})$, streptomycin $(100 \mu \mathrm{g} / \mathrm{mL})$, amphotericin B $(0.25 \mu \mathrm{m} / \mathrm{mL})$, and $2 \%$ fetal bovine serum (BioWhittaker) in $5 \% \mathrm{CO}_{2}$ at $37^{\circ} \mathrm{C}$. Microsporidia spore propagation and purification were performed as previously described in [5].

2.2. Recombinant Protein Expression and Antiserum Production. The gene encoding the "C1" Hsp70-related protein (ECU02_0100) was PCR amplified from E. cuniculi genomic DNA using the following primers; $5^{\prime}$-GGAATTCATGAACAAGGGTATGCTAG-3' and $5^{\prime}$-ACTCGAGGAGTTCTTCTCTCCCTATTTC-3'. The amplicon was cloned into the pET21a vector (EMD Biosciences, Inc., Madison, WI) using restriction endonucleases and ligation. Following transformation into Escherichia coli Rosetta Gami cells (EMD Biosciences) and induction with IPTG (isopropyl- $\beta$-Dthiogalactopyranoside), the bacterial harvest was sonicated in PBS containing 5\% SDS and $2 \% \beta$-mercaptoethanol. SDSPAGE gels were Coomassie stained, and Western analysis was performed using a histidine-tag-specific antibody (SigmaAldrich, St. Louis, MO) to confirm recombinant protein expression.

For purification, the bacterial pellet was sonicated in column chromatography binding buffer containing $8 \mathrm{M}$ urea and $20 \mathrm{mM}$ imidazole in $1 \mathrm{X}$ phosphate buffered saline. The supernatant was applied to an equilibrated nickel affinity column (GE Biosciences, Piscataway, JH). Following washes with binding buffer, the recombinant protein was eluted with 1X phosphate buffered saline containing $8 \mathrm{M}$ urea and $300 \mathrm{mM}$ imidazole. Fractions containing recombinant protein were combined and dialyzed against $10 \mathrm{mM}$ Tris buffer ( $\mathrm{pH}$ 7.4) with $0.5 \mathrm{mM}$ EDTA. The resulting dialysate was centrifuged, and the supernatant containing the protein was pooled and stored at $-20^{\circ} \mathrm{C}$ for further use.
For antiserum production, naïve rabbits were immunized with the recombinant $\mathrm{C} 1 \mathrm{Hsp} 70$-related protein using a 56-day immunization protocol conducted at a commercial facility (Proteintech Group, Inc., Chicago, IL). Antibodies from both pre- and postimmunized rabbits were purified from serum using protein $\mathrm{A} / \mathrm{G}$ affinity chromatography according to the manufacturer's recommendations (Thermo Fisher Scientific, Rockford, IL).

2.3. Spore Adherence Assays. Microsporidia spore adherence assays were performed as previously described in [3]. RK13 cells were seeded onto round glass coverslips in 12well plates and grown to confluence. To test adherence, purified diluted anti-C1 antibodies $(1 \mathrm{mg} / \mathrm{mL})$ or anti-EnP1 antibodies $(1 \mathrm{mg} / \mathrm{mL})$ [6] were incubated with $E$. cuniculi spores in medium on RK13 host cells for 4-hours on ice. The unbound spores were removed by washing with PBS, and the bound spores were quantified by immunofluorescence as described in [6]. The results are expressed as the percentage of adherent spores relative to control samples. Statistical significance was determined using the Student's $t$ test.

2.4. SDS-PAGE Analysis and Western Blotting. Onedimensional sodium dodecyl sulfate polyacrylamide gel electrophoresis (1D-SDS-PAGE) was performed with purified spore protein as previously described in [6]. For two-dimensional (2D) SDS-PAGE analysis, $1 \times 10^{9}$ purified E. cuniculi spores were used for protein sample preparation following the procedures and buffers recommended in the ReadyPrep 2D-Starter Kit (Biorad; Hercules, CA) with slight modifications. The spore pellet was digested for 30 minutes at boiling temperature in denaturing buffer containing $0.05 \%$ SDS and $0.1 \%$ 2-mercaptoethanol. The supernatant was transferred to a new tube, and the free SDS was removed using the SDS-Out Reagent (Pierce/Thermo Scientific; Rockford, IL). The buffer was exchanged for the ReadyPrep2D Rehydration/Sample buffer using a Microcon (YM-10) Centrifugal Filter Device (Millipore; Billerica, MA). The buffer volume equivalent of $2.5 \times 10^{8}$ spores was used to rehydrate two $11 \mathrm{~cm} \mathrm{pH} \mathrm{4-7} \mathrm{IPG} \mathrm{strips}$ according to the ReadyStrip IPG protocol (Biorad). The strips were focused using a Biorad Protean IEF cell and the standard recommendations for programming. For the second dimension, the gel strips were equilibrated in the kit Equilibration Buffer I and II and precast Criterion 8-16\% Tris-HCl SDS-PAGE gels (Biorad) were used. For Western blots, the gels were transferred as described in [6].

To identify the Hsp70-related proteins, gel spots from Coomassie stained 2D-SDS-PAGE gels were excised and submitted for commercial protein identification by trypsin digestion and tandem mass spectrometry using nanoliquid chromatography/tandem mass spectrometry (Midwest Bio Services, Overland Park, KS). The acquired data were analyzed using Sequest database searching software.

\section{Results}

3.1. Cloning and Heterologous Expression of E. cuniculi Recombinant Hsp70-Related Protein. To identify an internal 


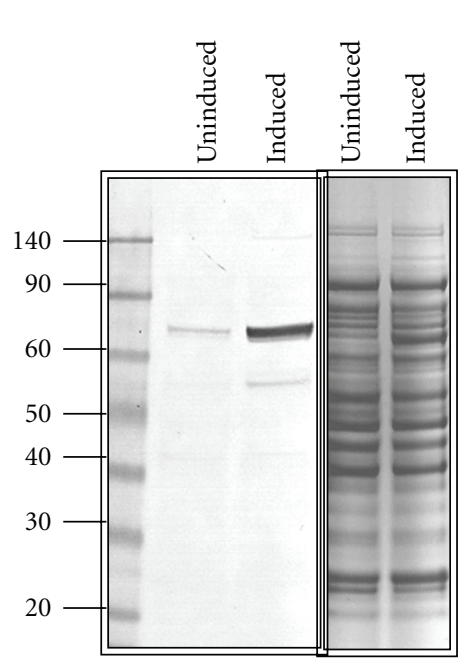

(a)

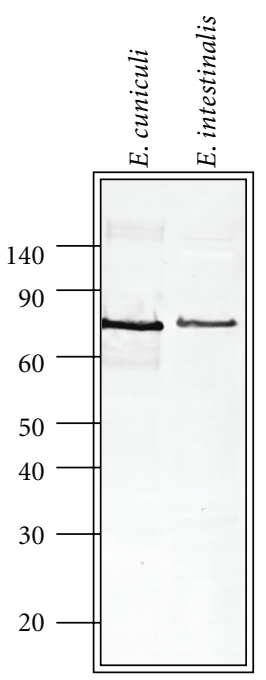

(b)

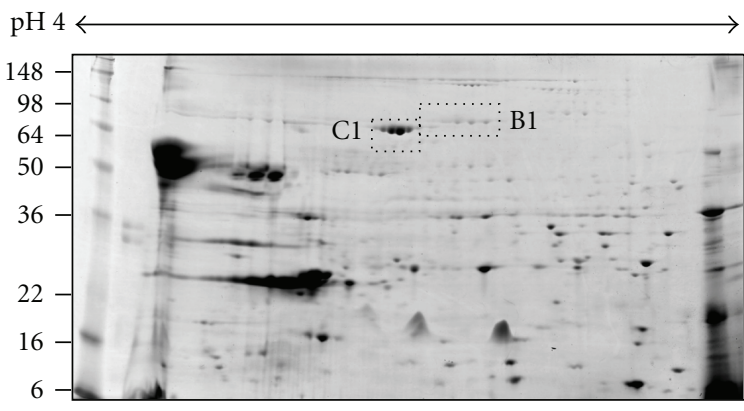

(c)

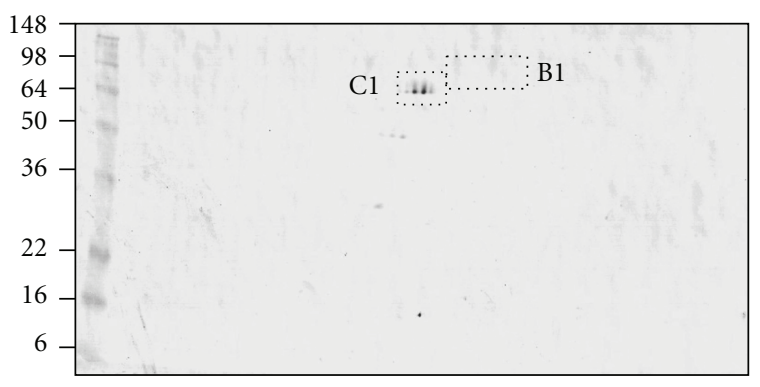

(d)

FIgURE 1: Heterologous expression of E. cuniculi C1 Hsp70 protein as a histidine fusion protein in E. coli and Western blot analysis using purified C1 antibodies. A Coomassie stained SDS-PAGE gel ((a), right panel) of uninduced and IPTG induced expression of the recombinant protein shows a $\sim 76 \mathrm{kDa}$ protein in the induced lane. A Western blot of the SDS-PAGE gel was performed using histidine-tag-specific antibodies ((a), left panel) confirmed the recombinant protein induction. (b) A single $\sim 76 \mathrm{kDa}$ band was detected on 1D Western blot of $E$. cuniculi and E. intestinalis total spore protein using purified C1 Hsp70 protein antibodies. (c) The C1 (ECU02_0100) and B1 (ECU03_0520) Hsp70-related proteins were identified from a Coomassie stained 2D SDS-PAGE gel of E. cuniculi total spore protein by MALDI-MS analysis of trypsin digested gel spots. (d) Western analysis of the 2D gel using the C1 specific antibodies detected only the C1 protein (d).

protein for comparison to spore surface proteins, we focused on heat-shock proteins (Hsp), which are usually located internally in the cytosol, endoplasmic reticulum, or mitochondria. Analysis of the E. cuniculi genome database revealed several candidate Hsp70-related genes, some of which have been characterized including the canonical mitochondrial organellar heat shock protein [7-9]. However, for our purposes, we selected a highly expressed Hsp70 family member from E. cuniculi (ECU02_0100; “C1”), which contains all three Hsp70 protein family signature motifs of conserved family members identified by Prosite database scanning [10]. In addition, this protein contains an $\mathrm{N}$ terminal signal peptide allowing it to be translocated into the endoplasmic reticulum (ER) and a C-terminal ER targeting sequence ("REEL"), which would retain the protein in the ER. 


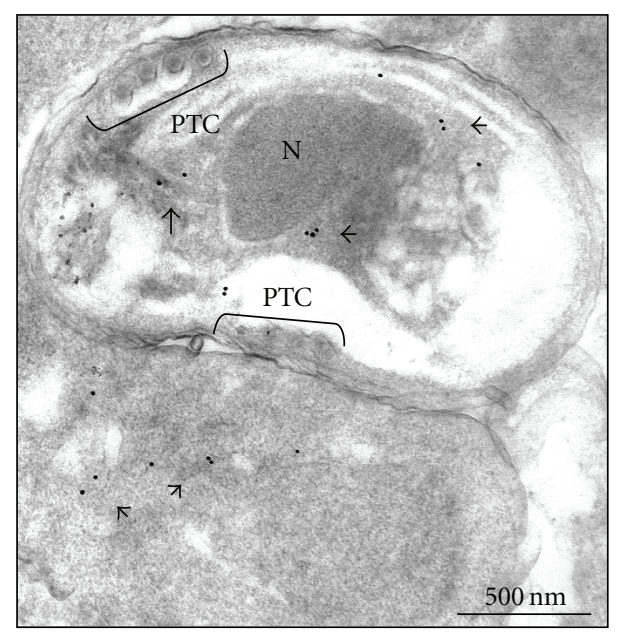

(a)

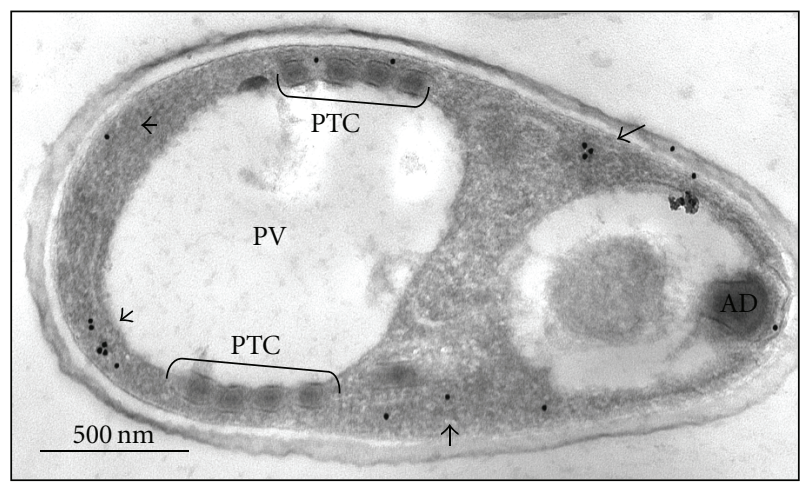

(b)

FIGURE 2: Immuno-TEM of E. cuniculi infected rabbit kidney cells. The infected cells were prepared according to the protocol described. Ultrathin Lowicryl resin sections were cut and reacted with C1 Hsp70 specific antibodies $(1: 10)$ and a secondary antibody conjugated to 15-nm gold particles $(1: 200)$. The developmental stages include immature meronts and sporonts (the lower and upper spores in (a), resp.) and a mature spore (b). Abbreviations are as follows: PTC, polar tube coil; N, nucleus; PV, posterior vacuole; AD, anchoring disk. Each bar indicates a 500-nm scale.

The open reading frame that encodes from the $\mathrm{N}$ terminal methionine residue to the C-terminal leucine residue immediately prior to the termination codon of $\mathrm{C} 1$ was amplified, cloned, and expressed in E. coli. The expressed recombinant protein was similar to the predicted size of $76.2 \mathrm{kDa}$ (Figure 1(a)) and was used to immunize naïve rabbits. In one-dimensional Western blot analysis using purified spore protein from both E. intestinalis and E. cuniculi, the anti-C1 Hsp70 protein antibodies recognized a single protein band from both species (Figure 1(b)). However, our analysis of the E. cuniculi genome database identified a second Hsp70-related protein with a predicted size of $74.8 \mathrm{kDa}$ (ECU03_0520; “B1"). Because the masses of these two proteins are so similar and the predicted amino acid identity is $28.3 \%$, the single band observed in 1D Westerns may represent recognition of both the $\mathrm{C} 1$ and B1 Hsps. Such reactivity would be difficult to distinguish using onedimensional SDS-PAGE. Therefore, two-dimensional SDSPAGE electrophoresis and Western blotting analysis were performed with purified E. cuniculi spore proteins and the anti-C1 Hsp70 antibodies. Matrix-assisted laser desorption ionization mass spectrometry analysis of trypsin digested Coomassie gel spots identified both the $\mathrm{C} 1$ and B1 Hsp70 proteins (Figure 1(c)). Peptide coverage represented 38 and $24 \%$ of the $\mathrm{C} 1$ and $\mathrm{B} 1$ proteins, respectively. Interestingly, the $\mathrm{B} 1$ protein, which is predicted to be $74.8 \mathrm{kDa}$, is slightly larger in mass on the 2D SDS-PAGE gel than the predicted $76.2 \mathrm{kDaC}$ Crotein. It is possible that the removal of the signal peptide from the $\mathrm{C} 1$ could account for the size discrepancy. Nonetheless, Western blotting of the two dimensional SDS-PAGE shows that the anti-C1 Hsp70 antibodies are specific for the $\mathrm{C} 1 \mathrm{Hsp} 70$-related protein and do not cross react with the similar sized B1 protein (Figure 1(d)).
3.2. Immunolocalization of C1 Hsp70-Like Protein in E. cuniculi Spores. To confirm that the C1 Hsp70-like protein does not localize to the spore wall, immunogold labeled transmission electron microscopy (immuno-TEM) of $E$. cuniculi infected RK13 cells was performed using the purified anti-C1 Hsp70 antibodies. The antibodies recognize protein in both immature (Figure 2(a)), and mature spores (Figure 2(b)). The C1 Hsp70 protein does not appear to be located in one specific area, but rather is spread throughout the cytoplasm. In microsporidia, the membranous ER and associated ribosomes of spores are difficult to visualize, especially in immunolocalization TEM resin. However, in structural studies, the ER has been located both surrounding the nucleus and in other parts of the cytoplasm [11]. The immunolabeling of the $\mathrm{C} 1 \mathrm{Hsp} 70$ protein in Figure 2 appears to match the ER structural profile. No significant immunolabeling was evident on the outside surfaces of developing or mature spores or within host cells that did not contain parasitophorous vacuoles (data not shown).

\subsection{Anti-C1 Antibodies Do Not Inhibit E. cuniculi Spore} Adherence to Host Cells. The previous studies have shown that microsporidia infection of host cells may involve an initial attachment of spores to host cell surfaces, which precedes spore activation, germination, and polar filament extrusion [3, 6]. Spore attachment, and thus host cell infection, can be inhibited with the addition of either sulfated glycosaminoglycans, a common host cell surface glycan, or exogenous endospore protein-1 (EnP1). EnP1 is found in both the endospore and exospore regions of spore walls and is an adherence ligand potentially involved in the spore activation process $[6,12]$. Addition of either recombinant EnP1 or anti-EnP1 antibodies to spore adherence assays 


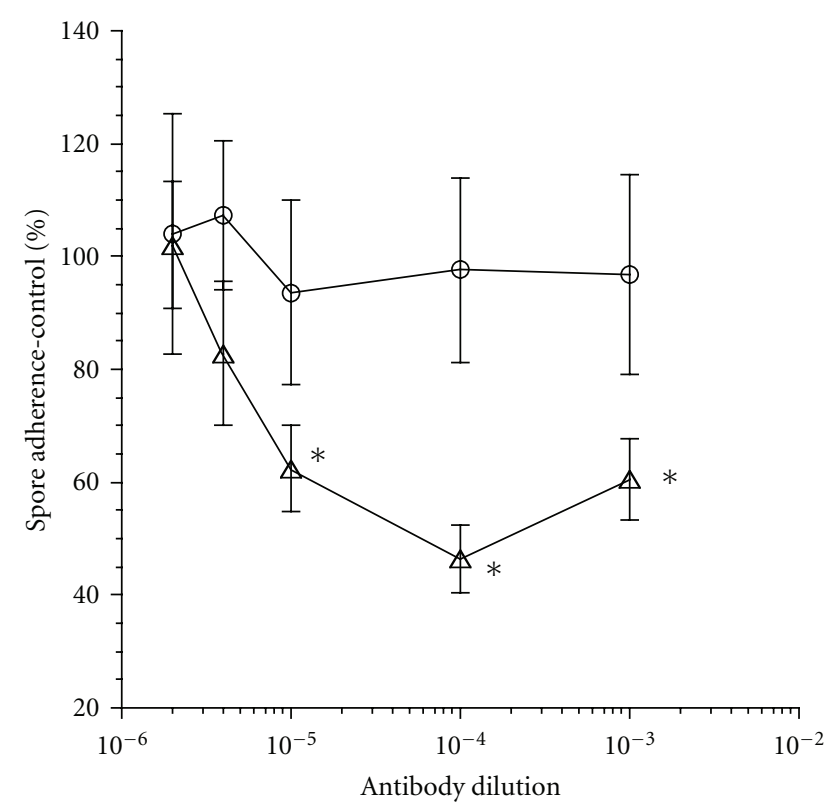

- Anti-HSP70

$\triangle$ Anti-EnP1

Figure 3: Purified antibodies specific for the internal C1 Hsp70 protein does not inhibit E. cuniculi spore adherence to rabbit kidney host cells. Increasing concentrations of $\mathrm{C} 1$ antibodies (open circles) or EnP1 specific antibodies (open triangle) were incubated with spores in the presence of confluent host cells. Control samples excluded antibodies. After 4-hours, unbound spores were removed by washing and the bound spores were quantified by immunofluorescence assay. Each antibody dilution sample was performed in triplicate. Statistical significance is indicated with asterisks $(P<.0001)$.

significantly reduces the number of adherent spores. To confirm that the anti-C1 Hsp70 antibodies, which specifically recognize the nonsurface associated ER Hsp70 protein, do not affect spore attachment, spore/host cell adherence assays were performed using both the anti-C1 antibodies and the anti-EnP1 antibodies (Figure 3). Adding increasing amounts of anti-EnP1 antibodies leads to dose-dependant decreases in spore adherence, as was expected. However, equivalent quantities of anti-C1 antibodies have no affect on spore adherence to host cell surfaces, confirming that the internally located C1 Hsp70 is not involved in adherence.

\section{Discussion}

The previous studies involving Hsp70 proteins of microsporidia have revolved around phylogeny, in part due to the fact that microsporidia are "amitochondriate" organisms [7-9, 13]. During microsporidia genome sequencing efforts, a mitochondria-associated heat shock protein was identified, despite the fact that microsporidia have no identifiable mitochondria organelle. Studies involving this Hsp eventually identified an "ancient" mitochondria organelle called a mitosome $[9,14]$. This discovery placed microsporidia in a small group of amitochondriates, which includes Giardia intestinalis, Trichomonas vaginalis, and Entamoeba histolytica $[14,15]$. Further studies revealed that several iron-sulphur cluster assembly proteins were located in the mitosome based on their co-localization with the mitosome-associated Hsp70 family member [16].

Most cells have multiple members of the Hsp70 family of heat shock proteins that function in a variety of manners. The most recognized functions of Hsp70s are to assist in protein folding and trafficking and coping with protein denaturation in response to increased stress, such as heat [4]. Interestingly, studies have shown that within the cell, Hsp70 family members may also exert a pro-survival affect, combating the intrinsic apoptotic pathway activation in neuronal cells [17]. Hsp72 inhibits the release of cytochrome$\mathrm{c}$ from the mitochondria, inhibits apoptosis inducing factor translocation to the nucleus, and interferes with recruitment of procaspase- 9 into the apoptosome [18]. Recently, it has also been shown that some Hsp70 family members can be released from cells to serve as a physiological alarm signal for cell trauma or to act as a pro- or anti-inflammatory mediators [19-21]. Either through active transport or passive release due to cellular destruction, the released Hsp proteins exert their affect beyond the cell from which they originated. In our immuno-TEM analysis, we did not see significant labeling in any host cell organelle. Nor was there significant labeling in the extracellular spaces within the parasitophorous vacuole indicating that the ER associated Hsp70-like protein may not be secreted. It remains to be seen whether the E. cuniculi cytosolic Hsp70-related protein (ECU03_0520; B1) that does not contain an ER retention signal or a signal peptide is released from developing or mature spores.

The $\mathrm{C} 1 \mathrm{Hsp} 70$ protein contains an ER retention signal at the C-terminal end. Although the ER has not been extensively studied in microsporidia, structural studies have identified the ER as membranous elements arranged in parallel cisternae covered by ribosomes [11]. These elements both surround the nucleus and are dispersed throughout the cytoplasm. Both the spore-wall and polar-tube proteins have predicted signal peptides for ER translocation and trafficking [22-24]. And, recent studies indicate that microsporidia have the necessary machinery, albeit reduced and modified, for translocation of polypeptide chains into the ER [25]. Furthermore, Golgi complex studies in microsporidia suggest they do not create budding vesicles with typical eukaryotic coat proteins, but have instead tubular networks that directly connect to the ER, the polar tube membrane, and the plasma membrane [26]. Thus, the extensive network of membranes would be distributed throughout the spore cytoplasm. The varied immuno-EM cytosolic labeling of $\mathrm{C} 1 \mathrm{Hsp} 70$ protein shown here would be indicative of an extensive membranous ER/Golgi secretory pathway.

In summary, we have cloned and expressed an ER associated member of the Hsp70 family from E. cuniculi. Antibodies generated against this protein specifically recognize $\mathrm{C} 1 \mathrm{Hsp} 70$ from microsporidia and localize it to internal structures of spores. Moreover, the anti-C1 antibodies did not inhibit spore adherence. As a result, the C1 Hsp70 protein and the antibody are important tools 
for research in the field of microsporidia and will be used as internal markers for comparisons during our studies on spore adherence.

\section{Acknowledgments}

The authors are thankful for Dr. Sara Davis-Hayman for critical reading of the paper and to the Electron Microscopy Core Facility at East Tennessee State University, Quillen College of Medicine for technical assistance.

\section{References}

[1] I. Desportes-Livage, "Microsporidia and other opportunistic protozoa in patients with acquired immunodeficiency syndrome (AIDS)," vol. 1, no. Clinical Microbiology and Infection, pp. 152-153, 1996.

[2] D. P. Kotler and J. M. Orenstein, "Clinical syndromes associated with microsporidiosis," Advances in Parasitology, vol. 40, pp. 321-349, 1998.

[3] J. R. Hayman, T. R. Southern, and T. E. Nash, "Role of sulfated glycans in adherence of the microsporidian Encephalitozoon intestinalis to host cells in vitro," Infection and Immunity, vol. 73, no. 2, pp. 841-848, 2005.

[4] F. U. Hartl, J. Martin, and W. Neupert, "Protein folding in the cell: the role of molecular chaperones Hsp70 and Hsp60," Annual Review of Biophysics and Biomolecular Structure, vol. 21, pp. 293-322, 1992.

[5] J. R. Hayman and T. E. Nash, "Isolating expressed microsporidial genes using a cDNA subtractive hybridization approach," Journal of Eukaryotic Microbiology, vol. 46, no. 5, pp. 21S-24S, 1999.

[6] T. R. Southern, C. E. Jolly, M. E. Lester, and J. R. Hayman, "EnP1, a microsporidian spore wall protein that enables spores to adhere to and infect host cells in vitro," Eukaryotic Cell, vol. 6, no. 8, pp. 1354-1362, 2007.

[7] E. Peyretaillade, V. Broussolle, P. Peyret, G. Méténier, M. Gouy, and C. P. Vivarès, "Microsporidia, amitochondrial protists, possess a $70-\mathrm{kDa}$ heat shock protein gene of mitochondrial evolutionary origin," Molecular Biology and Evolution, vol. 15, no. 6, pp. 683-689, 1998.

[8] A. Germot, H. Philippe, and H. Le Guyader, "Evidence for loss of mitochondria in microsporidia from a mitochondrialtype HSP70 in Nosema locustae," Molecular and Biochemical Parasitology, vol. 87, no. 2, pp. 159-168, 1997.

[9] B. A. P. Williams, R. P. Hirt, J. M. Lucocq, and T. M. Embley, "A mitochondrial remnant in the microsporidian Trachipleistophora hominis," Nature, vol. 418, no. 6900, pp. 865-869, 2002.

[10] N. Hulo, A. Bairoch, V. Bulliard et al., "The 20 years of PROSITE," Nucleic Acids Research, vol. 36, no. 1, pp. D245D249, 2008.

[11] J. Vavra and J. I. Larsson, "Structure of the microsporidia," in The Microsporidia and Microsporidiosis, pp. 7-84, American Society of Microbiology, Washington, DC, USA, 1999.

[12] I. Peuvel-Fanget, V. Polonais, D. Brosson et al., "EnP1 and EnP2, two proteins associated with the Encephalitozoon cuniculi endospore, the chitin-rich inner layer of the microsporidian spore wall," International Journal for Parasitology, vol. 36, no. 3, pp. 309-318, 2006.

[13] R. P. Hirt, B. Healy, C. R. Vossbrinck, E. U. Canning, and T. M. Embley, "A mitochondrial Hsp70 orthologue in
Vairimorpha necatrix: molecular evidence that microsporidia once contained mitochondria," Current Biology, vol. 7, no. 12, pp. 995-998, 1997.

[14] L. Burri, B. A. P. Williams, D. Bursac, T. Lithgow, and P. J. Keeling, "Microsporidian mitosomes retain elements of the general mitochondrial targeting system," Proceedings of the National Academy of Sciences of the United States of America, vol. 103, no. 43, pp. 15916-15920, 2006.

[15] N. Arisue, L. B. Sánchez, L. M. Weiss, M. Müller, and T. Hashimoto, "Mitochondrial-type hsp70 genes of the amitochondriate protists, Giardia intestinalis, Entamoeba histolytica and two microsporidians," Parasitology International, vol. 51, no. 1, pp. 9-16, 2002.

[16] A. V. Goldberg, S. Molik, A. D. Tsaousis et al., "Localization and functionality of microsporidian iron-sulphur cluster assembly proteins," Nature, vol. 452, no. 7187, pp. 624-628, 2008.

[17] R. G. Giffard, L. Xu, H. Zhao et al., "Chaperones, protein aggregation, and brain protection from hypoxic/ischemic injury," The Journal of Experimental Biology, vol. 207, no. 18, pp. 3213-3220, 2004.

[18] K. Ruchalski, H. Mao, S. K. Singh et al., "HSP72 inhibits apoptosis-inducing factor release in ATP-depeleted renal epithelial cells," American Journal of Physiology-Cell Physiology, vol. 285, no. 6, pp. C1483-C1493, 2003.

[19] S. S. Mambula and S. K. Calderwood, "Heat induced release of Hsp70 from prostate carcinoma cells involves both active secretion and passive release from necrotic cells," International Journal of Hyperthermia, vol. 22, no. 7, pp. 575-585, 2006.

[20] S. Todryk, A. A. Melcher, N. Hardwick et al., "Heat shock protein 70 induced during tumor cell killing induces Th1 cytokines and targets immature dendritic cell precursors to enhance antigen uptake," Journal of Immunology, vol. 163, no. 3, pp. 1398-1408, 1999.

[21] R. G. Giffard, R.-Q. Han, J. F. Emery, M. Duan, and J. F. Pittet, "Regulation of apoptotic and inflammatory cell signaling in cerebral ischemia: the complex roles of heat shock protein 70," Anesthesiology, vol. 109, no. 2, pp. 339-348, 2008.

[22] J. R. Hayman, S. F. Hayes, J. Amon, and T. E. Nash, "Developmental expression of two spore wall proteins during maturation of the microsporidian Encephalitozoon intestinalis," Infection and Immunity, vol. 69, no. 11, pp. 7057-7066, 2001.

[23] W. Bohne, D. J. P. Ferguson, K. Kohler, and U. Gross, "Developmental expression of a tandemly repeated, glycineand serine- rich spore wall protein in the microsporidian pathogen Encephalitozoon cuniculi," Infection and Immunity, vol. 68 , no. 4, pp. 2268-2275, 2000.

[24] E. M. Keohane, G. A. Orr, P. M. Takvorian et al., "Polar tube proteins of microsporidia of the family encephalitozoonidae," Journal of Eukaryotic Microbiology, vol. 46, no. 1, pp. 1-5, 1999.

[25] R. F. Waller, C. Jabbour, N. C. Chan et al., "Evidence of a reduced and modified mitochondrial protein import apparatus in microsporidian mitosomes," Eukaryotic Cell, vol. 8, no. 1, pp. 19-26, 2009.

[26] G. V. Beznoussenko, V. V. Dolgikh, E. V. Seliverstova et al., "Analogs of the Golgi complex in microsporidia: structure and avesicular mechanisms of function," Journal of Cell Science, vol. 120, no. 7, pp. 1288-1298, 2007. 

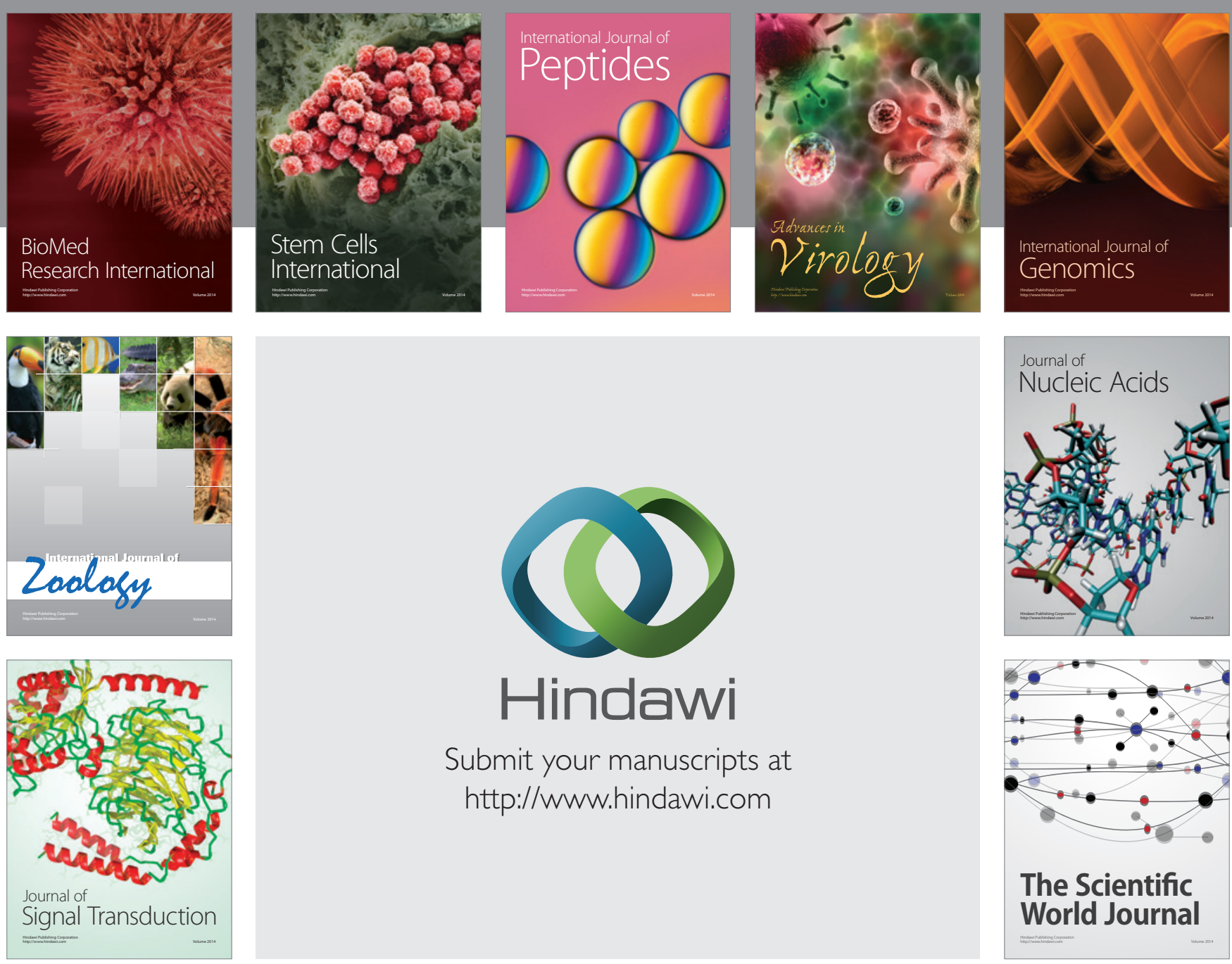

Submit your manuscripts at

http://www.hindawi.com
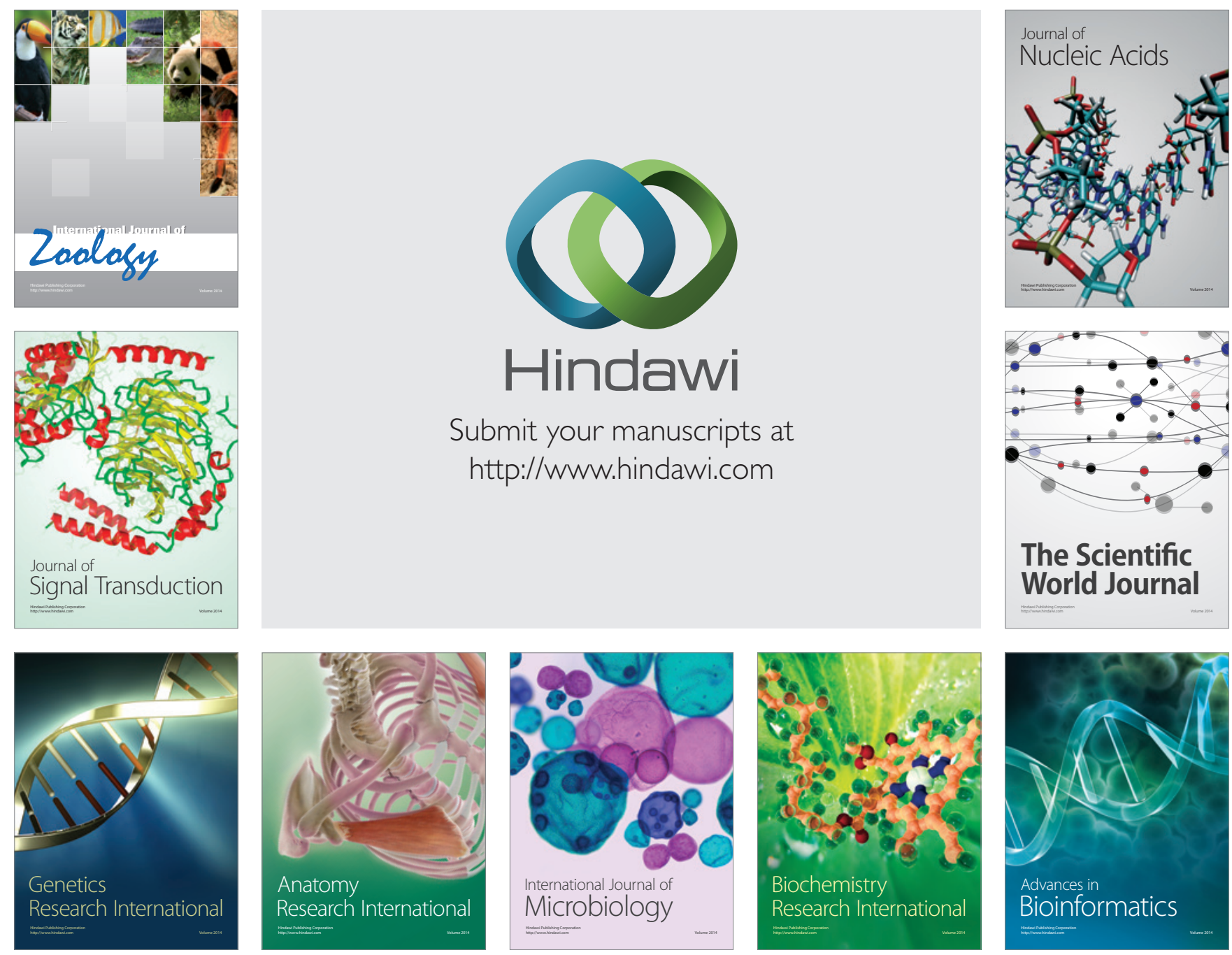

The Scientific World Journal
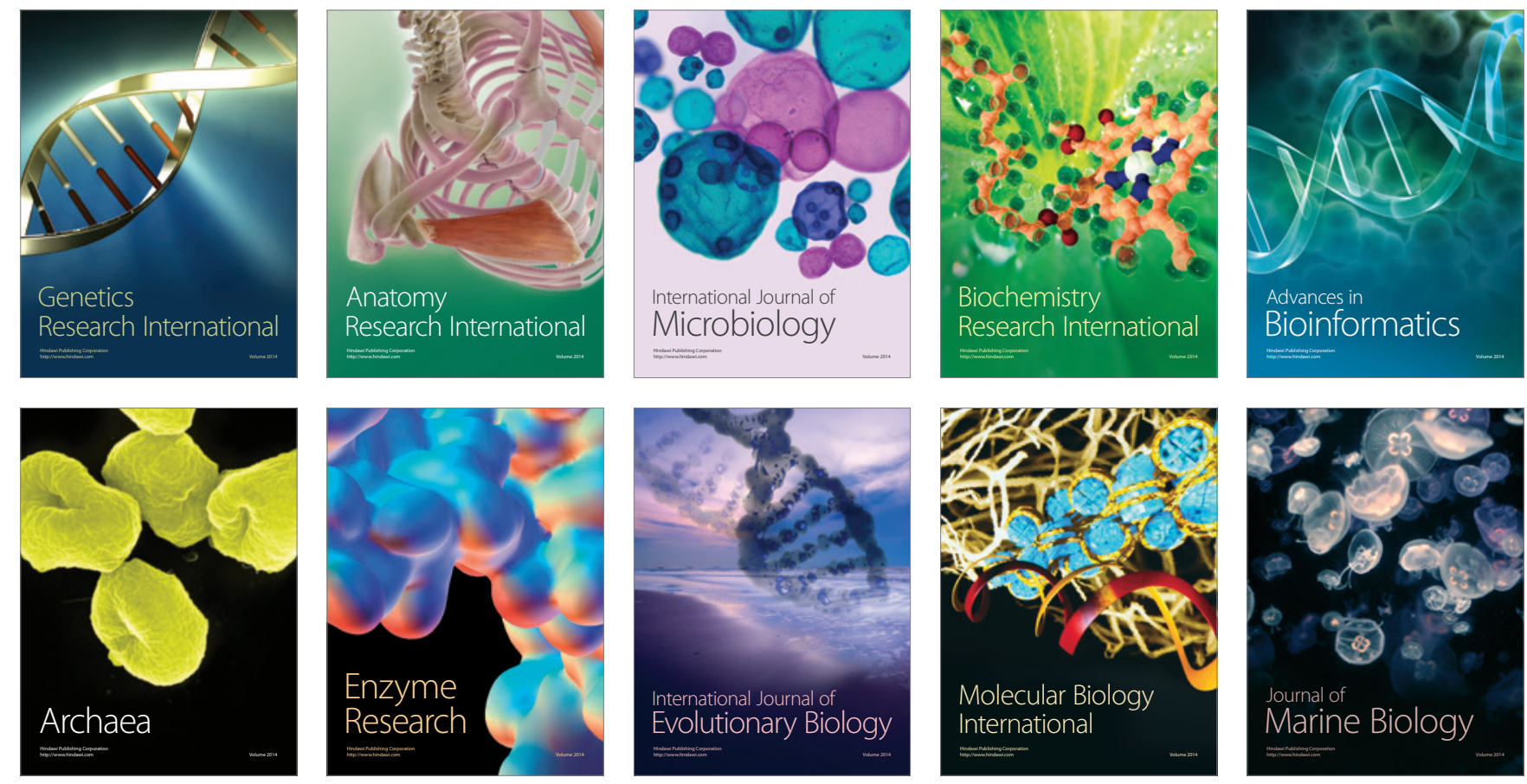